\title{
PENGARUH RASIO RGEC, BANK SIZE, MARKET VALUE, SERTA VARIABEL MAKRO EKONOMI TERHADAP PREDIKSI FINANCIAL DISTRESS MENGGUNAKAN CD-INDEX
}

\author{
Wanda Hamidatun Nisak \\ Universitas Negeri Surabaya \\ wanda.17080574001@mhs.unesa.ac.id
}

\begin{abstract}
The Bank is a financial institution that functions to accumulate and distribute funds to the public and providing other banking services. In channelling funds, banks are not protected from the internal and external risks that cause financial difficulties. This study examines the influence of RGEC factors, bank size, market value, and macroeconomic to predict financial distress using the Crisis and Default Index. RGEC factors used in this study is risk profile which is proxy by NPL and LDR, good corporate governance is proxy of the size of board directors, earnings proxied by ROA, ROE, NIM, BOPO, and capital is proxied by CAR. The variable of bank size and market value is proxied by PBV and PER. While the macroeconomic variables used are economic growth, inflation, and exchange rates. This study used 19 banks in the BUSN group as a research sample during 2015-2019. The result showed that internal factors and bank size did not significantly influence the prediction of financial distress. Market value variable proxied by PBV has a significant negative effect on the prediction of financial distress. This is important for internal bank parties to keep stock prices from falling and investors are interested in investing; PER and macroeconomic variables do not significantly affect the prediction of financial distress because good internal banking fundamentals face changes in economic conditions. There is no influence of variables with financial distress because these variables appropriate with Bank Indonesia and $B U S N$ are implementing them correctly.
\end{abstract}

Keywords: bank size; financial distress; macroeconomic; market value; RGEC

\section{PENDAHULUAN}

Bank berperan penting dalam suatu negara khususnya di bidang pekonomian salah satunya sebagai agent of development, yaitu lembaga keuangan yang berperan dalam pembangunan perekonomian dengan cara mengelola dana (Budisantoso \& Nuritomo, 2018:9). Pentingnya peran yang dimiliki membuat bank rentan mengalami risiko sistematik. Menurut Wibowo \& Ham (2016), ketika bank memiliki peluang besar dalam mengalami kegagalan secara sistematis bank di dalamnya juga akan mengalami kegagalan, akibatnya risiko sistematik dari sistem perbankan semakin besar. Krisis keuangan pada tahun 1997-1998 di Asia disebabkan oleh negara Thailand mendeklarasikan ketidakmampuannya membayar hutang luar negeri. Kerugian yang dialami oleh Thailand karena memertahankan mata uangnya membuat mata uang bath terdepresiasi (kompas.com, 2020). Kondisi ini menyebabkan gejolak perekonomian di negara Asia Tenggara khususnya Indonesia yang nilai tukar rupiah ikut melemah. Indonesia meminta bantuan kepada IMF untuk menangani masalah ini yaitu melikuidasi 16 bank nasional karena adanya kebijakan pengetatan likuiditas, namun kondisi ini semakin memburuk karena masyarakat berbondong-bondong menarik dananya yang telah disimpan (bank runs).

Lemahnya perekonomian Indonesia juga terjadi pada tahun 2008 di mana Amerika Serikat mudah dalam memberikan kredit perumahan (suprime mortage), kesalahan dalam memberikan kredit kepada debitur yang sering mengalami berbagai kasus seperti memiliki catatan kredit yang buruk membuat kredit diberikan berisiko tinggi (finance.detik.com, 2009). Kondisi terparah yaitu debitur tidak mampu membayar, sehingga gelombang gagal bayar yang tinggi membuat harga rumah jatuh dan menyeret investor maupun lembaga penjaminan ke dalam persoalan likuiditas yang besar. Lemahnya likuiditas dan perekonomian terasa pada kondisi perbankan tanah air, yang mana terjadi kegentingan dan terdapat potensi mengalami capital flight (Pristanti \& Musdholifah, 2020). 
Permasalahan mengenai kewajiban jangka pendek yang harus dipenuhi seringkali terjadi di Indonesia, hal ini yang menjadi faktor utama terjadinya financial distress yang dapat dilihat dari nilai Loan to Deposit Ratio (LDR). Rasio likuiditas menghitung apakah bank mampu dalam membayar hutang yang sudah jatuh tempo atau kemampuan dalam memenuhi dana deposan yang tertagih serta kredit yang telah diajukan dapat tercukupi, besarnya rasio ini menandakan tingginya tingkat likuiditas bank (Kasmir, 2014:315). Bank Indonesia menganjurkan batas atas rasio LDR adalah 92\% sedangkan batas bawah adalah 78\% (Kristanti, 2014). Tahun 2018 dan 2019 nilai rasio LDR bank melampaui batas yang ditetapkan Bank Indonesia, per Agustus 2018 LDR perbankan mencapai angka 93,19\% dan akhir tahun 2019 LDR bank mencetak angka 94,66\% (infobanknews.com, 2018; financial.bisnis.com, 2019). Kondisi ini menyababkan kesehatan bank menurun dan probabilitas bank mengalami financial distress semakin tinggi.

Financial distress adalah kondisi bangkrutnya perusahaan maupun lembaga keuangan ditandai dengan sulitnya keuangan yang dihadapi (Siregar \& Fauzie, 2012). Financial distress atau kondisi kebangkutan dapat dilihat dari nilai EPS (Earning per Share), karena dapat melihat prospek perbankan jangka panjang (Andari \& Wiksuana, 2017). Berdasarkan perhitungan EPS dari tiga kelompok bank yaitu Bank BUMN, Bank Umum Swasta Nasional (BUSN) dan Bank Pemerintah Daerah (BPD) menunjukkan bahwa bank BUSN yang mengalami pergerakan kumulatif paling tajam, namun kinerja bank BUSN pada tahun 2018 sangat berkilau, baik dari segi kinerja keuangan, performa dari sisi intermediasi maupun indikator tingkat kesehatan bank lainnya (beritasatu.com, 2018). Kesenjangan antara data EPS dengan kinerja bank membuat kelompok bank BUSN menarik untuk dilakukan penelitian lebih lanjut. CD Indeks sebagai metode untuk prediksi financial distress lebih baik jika digunakan karena menggabungkan empat faktor risiko yaitu risiko likuiditas, risiko kredit, risiko nilai tukar, dan risiko perubahan suku bunga.

Permasalahan di bidang keuangan yang menyerang perusahaan baik skala kecil maupun skala besar sudah menjadi hal yang menakutkan. Banyak perusahaan yang menghindari permasalahan ini, padahal jika permasalahan keuangan tidak segera diatasi menyebabkan hambatan dalam kegiatan operasional, dan kondisi terparah yaitu terjadinya kebangkrutan (Sulastri \& Zannati, 2018). Penelitian di bidang keuangan menarik untuk diteliti lebih lanjut karena peran keuangan sangat besar bagi perusahaan, apalagi sektor perbankan menjadi lalu lintas segala macam transaksi dan pembayaran. Oleh karena itu objek yang diteliti yaitu bank, terutama bank umum swasta nasional (BUSN). Jika perbankan mengalami kesulitan keuangan dampak yang dialami tidak hanya pihak internal tetapi juga shareholder dan stakeholder. Faktor yang dapat digunakan untuk menilai kesehatan bank adalah faktor internal dari bank itu sendiri, market value, dan variabel makro ekonomi. Penelitian yang menggunakan variabel market value sedikit digunakan, padahal jika nilai pasar saham perbankan baik maka dapat mendorong investor untuk menanamkan saham dan bank akan mendapatkan tambahan suntikan dana. Menurut peraturan dari Bank Indonesia Nomor 13/1/PBI/2011 tanggal 5 Januari 2011 Tentang Penilaian Kesehatan Bank Umum, Bank Indonesia menetapkan metode RGEC yang menggunakan empat faktor yaitu risk profile (profil risiko), good corporate governance (tata kelola perusahaan), earning (pendapatan), dan capital (permodalan) dengan menggunakan pendekatan Risk Based Bank Rating (RBBR).

Financial distress dengan menggunakan indikator risk profile dapat diukur dengan rasio NPL dan rasio LDR. Nilai NPL tinggi menandakan kredit macet semakin tinggi pula sehingga bank akan kekurangan simpanan dana dan kehilangan kesempatan memeroleh pendapatan dari kredit yang diberikan (Pristanti \& Musdholifah, 2020). Pernyataan ini sejalan dengan Haq \& Harto (2019), semakin tinggi nilai NPL menandakan bahwa kualitas kredit yang diberikan semakin buruk karena adanya nasabah yang gagal dalam melakukan pembayaran kewajiban. Namun Shidiq \& Wibowo (2017), Betz et al. (2014), Wulandari et al. (2017), Choirina \& Yuyetta (2015), dan Nuranto \& Ardiansari (2017), menyatakan LDR tidak memiliki hubungan dengan financial distress.

Indikator good corporate governace dapat diproksikan dengan ukuran dewan direksi. Menurut Rahmawati \& Khoiruddin (2017), banyaknya dewan direksi dapat menentukan keputusan yang 
Wanda Hamidatun Nisak. Pengaruh Rasio RGEC, Bank Size, Market Value, serta Variabel Makro Ekonomi terhadap Prediksi Financial Distress Menggunakan CD-Index

diambil lebih efektif. Namun menurut Sadida (2018), Andari \& Wiksuana (2017), dan Haq \& Harto (2019), financial distress tidak bisa diukur dengan banyaknya dewan direksi.

Financial distress dengan menggunakan indikator earning meliputi ROA, ROE, NIM dan BOPO. Tingginya nilai ROA dapat memerkecil terjadinya financial distress, karena pengelolaan aset yang benar dapat menciptakan pendapatan optimal (Andari \& Wiksuana, 2017). Laba yang dihasilkan akan tinggi karena efisien dalam pengelolaan modal sendiri dapat meningkatkan nilai ROE (Shidiq \& Wibowo, 2017; Baselga et al., 2015) Semakin tinggi nilai rasio NIM sebagai tanda bahwa bank mampu dalam mengelola aset untuk menghasilkan bunga yang dapat meminimalisir terjadinya financial distress (Bestari \& Rohman, 2013). Nilai BOPO yang tinggi menandakan bahwa bank tidak dapat menekan biaya operasionalnya, sehingga sisi kewajiban lebih besar daripada sisi asetnya, (Musdholifah et al.,2020); Theodorus \& Artini (2018). Siregar \& Fauzie (2012), dan Nugroho (2012) menemukan bahwa ROA, ROE, NIM, dan BOPO tidak dapat mendeteksi terjadinya financial distress.

Pengukuran financial distress selanjutnya menggunakan indikator capital diproksikan dengan rasio CAR (Capital Adequency Ratio). Permodalan yang tinggi dapat menutup kerugian dari aset, sehingga dapat menghindari risiko terjadinya financial distress (Sadida, 2018). Kondisi financial distress tidak terdeteksi dengan rasio CAR (Haq \& Harto, 2019).

Indikator selanjutnya adalah ukuran bank dapat dihitung dari banyaknya aset bank yang bersangkutan. Semakin baik perbankan tersebut mengelola aset, dan mampu membayar hutangnya sebagai tanda bahwa aset yang dimiliki bank tinggi sehingga berpeluang kecil dalam menghadapi kesulitan keuangan (Baselga et al., 2015). Theodorus \& Artini (2018) tidak bisa membuktikan pengaruh bank size terhadap financial distress.

Pengukuran financial distress selanjutnya menggunakan indikator market value diproksikan dengan PBV dan PER. Nilai PBV tinggi menandakan bahwa performa bank baik dan profitabilitas bank juga tinggi, sehingga bank tidak mengalami kesulitan keuangan (Choirina \& Yuyetta, 2015). Gunsel (2012), menyatakan tumbuhnya laba sebagai pertanda tingginya nilai PER sehingga memberikan sinyal baik untuk investor membeli saham. Sedangkan Kuncoro \& Agustina (2017), bahwa rasio PBV dan PER tidak bisa mendeteksi terjadinya financial distress pada perbankan.

Pengukuran financial distress selanjutnya menggunakan indikator makro ekonomi melalui rasio Gross Domestik Produk (GDP), inflasi, dan nilai tukar. Ketika pertumbuhan ekonomi suatu negara meningkat dan stabil maka kemungkinan terjadinya financial distress kecil (Wulandari et al., 2017; Baselga et al., 2015). Tingginya inflasi menandakan perekonomian negara melemah (Musdholifah et al., 2013). Lemahnya nilai tukar membuat mata uang akan terdepresiasi dan peluang bank mengalami financial distress semakin tinggi (Mahmood et al., 2014). Namun Musdholifah et al. (2020), mendapatkan hasil jika variabel makro ekonomi yang diproksikan dengan GDP, inflasi dan nilai tukar tidak bisa digunakan untuk memprediksi kondisi financial distress.

Tujuan penelitian ini untuk mengetahui pengaruh rasio risk based bank rating, market value, bank size dan variabel makro ekonomi terhadap financial distress dengan model CD Indeks pada kelompok bank BUSN untuk peringatan dini sebelum terjadinya kebangkrutan. Hasil penelitian diharapkan dapat membantu dalam pengambilan keputusan dan mendeteksi financial distress pada BUSN.

\section{KAJIAN PUSTAKA DAN PENGEMBANGAN HIPOTESIS}

\section{Teori Krisis Keuangan Model Generasi Pertama (The first-generation model)}

Krisis ini disebabkan ketidakstabilan kondisi ekonomi dan defisit anggaran akibat terjadinya krisis mata uang. Teori ini diperkenalkan pertama kali oleh Krugman (1979), krisis keuangan ini terjadi karena krisis pada mata uang atau krisis neraca pembayaran akibat perekonomian suatu negara yang lemah. Lemahnya perekonomian ini diakibatkan banyaknya speculator yang membeli valuta asing untuk mendapatkan keuntungan yang besar dengan jangka waktu yang pendek sehingga dapat memperlemah mata uang domestik. Selain itu pada generasi pertama ini ditandai dengan 
meningkatnya peredaran jumlah uang, tingginya tingkat inflasi, turunnya cadangan devisa, dan nilai mata uang domestik pada batas overvalued terhadap mata uang asing (Musdholifah et al., 2013; Wulandari et al., 2017).

\section{Teori Krisis Keuangan Model Generasi Kedua (The second-generation model)}

Berkembangnya model ini dijelaskan oleh Obstfeld (1986) atas kelemahan model generasi pertama. Dalam model ini dijelaskan mengenai kepanikan dari pemegang likuiditas, kepanikan nasabah yang telah menyimpan uangnya di bank karena asimetri informasi tentang kinerja perbankan sehingga nasabah menarik uang yang disimpan di bank secara besar-besaran (bank runs). Keadaan bank runs dapat menimbulkan risiko sistematik, yang mana nasabah mendapatkan berita asimetris dari kejadian acak (Simorangkir, 2011). Meskipun fundamental perekonomian tidak ikut tergoncang, kejadian bank runs sebagai akibat dari kurangnya likuiditas bank menyebabkan terjadinya krisis.

\section{Financial Distress}

Platt \& Platt (2002) mengemukakan tahap terjadinya financial distress ditandai dengan lemahnya kondisi keuangan perbankan maupun perusahaan. Kondisi financial distress dan kondisi keuangan yang dialami oleh perbankan dapat dilihat dari laporan keuangan (Siregar \& Fauzie, 2012). Penyebab financial distress menurut Rodoni \& Ali (2010:170) antara lain (1) ketidakcukupan modal yang dimiliki, (2) besarnya beban hutang dan bunga, (3) menderita kerugian. Banyak model yang dikembangkan untuk mengukur kesehatan dan kinerja bank diantaranya yaitu Altman Z-Score, Zmijewski, Bankometer, Springate dan lain-lain. Namun metode ini belum berhasil sehingga ada pengembangan model baru yang dikenal CD Index (Musdholifah, 2015). CD Index dapat digunakan sebagai alat ukur untuk mengidentifikasi kondisi distress maupun non-distress. Model CD Indeks layak digunakan untuk analisis kondisi perbankan karena tingkat akurasi mencapai 58,2\% dan masih sedikit ditemui di Indonesia. (Prianti \& Musdholifah, 2018). Formulasi CD Index pada persamaan (1).

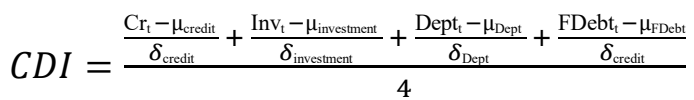

Ketetangan :

$\mu_{\text {Credit }}=$ rata-rata banyaknya kredit (credit) selama periode ke-t

$\mu_{\text {Invest }}=$ rata-rata banyaknya investasi (investment) selama periode ke-t

$\mu_{\text {Dept }}=$ rata-rata banyaknya Dana Pihak Ketiga selama periode ke-t

$\mu_{\text {Debt }}=$ rata-rata banyaknya pinjaman luar negeri selama periode ke-t

$\delta_{\text {Credit }}=$ standar deviasi kredit $($ credit) selama periode ke-t

$\delta_{\text {Invest }}=$ standar deviasi investasi (investment) selama periode ke-t

$\delta_{\text {Dept }}=$ standar deviasi Dana Pihak Ketiga selama periode ke-t

$\delta_{\text {Debt }}=$ standar deviasi pinjaman luar negeri selama periode ke-t

\section{Risk Profile yang diproksikan dengan NPL}

Rasio NPL menunjukkan kemampuan manajemen bank dalam pengelolaan kredit yang bermasalah atas kredit yang diberikan (Pristanti \& Musdholifah, 2020). Semakin tinggi nilai NPL menunjukkan kredit bermasalah lebih besar daripada kredit lancar sehingga menimbulkan masalah keuangan. Rumus menghitung risiko kredit menurut penelitian dari Yacheva et al. (2016) pada persamaan (2).

$N P L=\frac{\text { Kredit Bermasalah }}{\text { Total Kredit }} X 100 \%$.

\section{Risk Profile yang diproksikan dengan LDR}

Rasio LDR digunakan untuk mengukur kemampuan bank dalam membayar dana masyarakat serta modal sendiri dengan mengandalkan kredit yang telah didistribusikan ke masyarakat (Siregar \& Fauzie, 2012). Tingginya nilai rasio LDR menandakan likuiditas bank minim yang akan menurunkan kesehatan bank. Rumus untuk menghitung risiko likuiditas proksi LDR berdasarkan Yacheva et al., (2016) pada persamaan (3). 
Wanda Hamidatun Nisak. Pengaruh Rasio RGEC, Bank Size, Market Value, serta Variabel Makro Ekonomi terhadap Prediksi Financial Distress Menggunakan CD-Index

$L D R=\frac{\text { Total } \text { Kredit } \text { yang Diberikan }}{\text { Total Dana Pihak Ketiga }} X 100 \%$

\section{Good Corporate Governance (GCG) yang dihitung dengan Ukuran Dewan Direksi}

Penerapan GCG ialah kebijakan yang diterapkan oleh bank dalam mengelola perusahaan untuk menciptakan nilai tambah kepada shareholder dan stakeholder dalam jangka panjang (Pristanti \& Musdholifah, 2020). Kesalahan dalam pengambilan keputusan baik secara langsung maupun tidak oleh manajemen bank merupakan cerminan dari lemahnya kualitas penerapan GCG yang berimbas pada kinerja bank yang menurun (Hanifah \& Purwanto, 2013). Perhitungan GCG sebagai proksi ukuran dewan direksi menurut Prianti \& Musdholifah (2018) pada persamaan (4).

DirSize $=$ Sanggota dewan direksi pada periode $t$

\section{Earning yang diproksikan dengan ROA}

ROA melambangkan kesanggupan bank dalam menghasilkan keuntungan dari seluruh aktiva yang dimilikinya, tingginya nilai ROA menandakan bahwa bank mampu dalam menghasilkan laba yang optimal (Sofiasani \& Gautama, 2016; Theodorus \& Artini, 2018). Menurut Yacheva et al. (2016) rasio ini dihitung dengan rumus (5).

$R O A=\frac{\text { Laba Sebelum Pajak }}{\text { Rata-Rata } \text { Total Aset }} X 100 \%$

\section{Earning yang diproksikan dengan ROE}

ROE digunakan untuk memperkirakan besarnya laba bersih yang dihasilkan dari modal yang dimiliki (Pristanti \& Musdholifah, 2020). Tingginya nilai ROE menandakan bahwa bank mampu mengelola modal untuk menghasilkan laba bersih, rumus untuk menghitung rasio ini menurut Yacheva et al. (2016) pada persamaan (6).

ROE $=\frac{\text { Laba Setelah Pajak }}{\text { Modal Sendiri }} X 100 \%$

\section{Earning yang diproksikan dengan NIM}

Kekuatan aktiva produktif yang dimiliki oleh bank dalam menghasilkan pendapatan bunga bersih dapat dilihat dari rasio NIM (Sadida, 2018). Semakin besar rasio NIM maka pengelolaan aktiva produktif untuk menghasilkan pendapatan bunga bersih semakin meningkat (Shidiq \& Wibowo, 2017). Rumus untuk menghitung NIM menurut Siregar \& Fauzie (2012) pada persamaan (7).

$N I M=\frac{\text { Pendapatan Bunga Bersih }}{\text { Rata-Rata Aktiva Produktif }} X 100 \%$

\section{Earning yang diproksikan dengan BOPO}

Pengelolaan biaya operasional terhadap pendapatan operasional dapat dilihat dari rasio BOPO, tingginya rasio ini menandakan bahwa biaya operasional yang dikeluarkan oleh bank gagal dan berimbas pada menurunnya pendapatan operasional (Kurniasari \& Ghozali, 2013; Pristanti \& Musdholifah, 2020). Rumus untuk menghitung BOPO yang dimiliki oleh bank menurut penelitian dari Siregar \& Fauzie (2012) pada persamaan (8).

BOPO $=\frac{\text { Biaya Operasional }}{\text { Pendapatan Operasional }} \times 100 \%$

\section{Capital yang diproksikan dengan CAR}

Rasio CAR menggambarkan kemampuan bank dalam memertahankan modalnya dan kesanggupan pihak manajemen dalam mengawasi, mengukur dan mengontrol berbagai risiko yang bisa memengaruhi modal inti dan pelengkap (Kuncoro \& Agustina, 2017). Penurunan aset dapat ditutupi dengan rasio kecukupan modal, rumus yang digunakan untuk menghitung CAR menurut penelitian dari Siregar \& Fauzie (2012) pada persamaan (9).

$C A R=\frac{\text { Modal Bank }}{A T M R} X 100 \%$ 


\section{Bank Size}

Kualitas dan banyaknya aset dapat digunakan untuk melihat ukuran bank, bank dengan kualitas aset yang baik dapat terhindar dari kondisi yang bermasalah, karena nasabah maupun investor memberikan kepercayaan dengan menanamkan investasi di bank tersebut (Bestari \& Rohman, 2013). Rumus yang digunakan untuk menghitung bank size menurut dari Theodorus \& Artini (2018) pada persamaan (10).

Size $=\operatorname{Ln}($ Total Asset $)$

\section{Market Value yang diproksikan dengan rasio PBV}

Rasio PBV berfungsi untuk memprediksi profitabilitas bank yang berhubungan dengan nilai buku, PBV yang tinggi sebagai pertanda bahwa kinerja bank dalam kondisi yang baik, sehingga pihak manejemen dengan cepat menyampaikan informasi yang baik tentang perusahaan kepada pemegang saham (Kuncoro \& Agustina, 2017). Rumus yang digunakan dalam menghitung PBV menurut Purwohandoko (2009:48) pada persamaan (11).

$P B V=\frac{\text { Harga Per Lembar Saham }}{\text { Nilai Buku Ekuitas Per Lembar Saham }} X 100 \%$

\section{Market Value yang diproksikan dengan PER}

Price to Earning Ratio digunakan untuk mengukur pendapatan investor yang dilihat dari harga saham, penurunan nilai rasio PER akan diikuti dengan penurunan laba di masa depan, yang menjadi risiko dan memberikan sinyal buruk kepada pihak eksternal (Choirina \& Yuyetta, 2015). Rumus yang digunakan dalam menghitung PER menurut Purwohandoko (2009:48) pada persamaan (12).

$P E R=\frac{\text { Harga Per Lembar Saham }}{\text { Earning Per Share }(E P S)} X 100 \%$

\section{Pertumbuhan Ekonomi yang diukur dengan GDP}

GDP salah satu indikator ekternal yang mengukur financial distress pada perbankan maupun lembaga yang lain, penurunan pertumbuhan ekonomi mengindikasikan pada penurunan aktivitas ekonomi baik pada sektor riil maupun sektor keuangan (Shidiq \& Wibowo, 2017). Rasio ini dirumuskan dengan perubahan persentase GDP riil dalam tahun, rumus GDP riil menurut Prianti \& Musdholifah (2018) pada persamaan (13).

GDP riil $_{\mathrm{t}}=\frac{\mathrm{GDP}_{\mathrm{t}}-\mathrm{GDP}_{\mathrm{t}-1}}{\mathrm{GDP}_{\mathrm{t}-1}} \times 100 \%$

\section{Inflasi}

Tingginya nilai inflasi akan berhubungan dengan tingginya suku bunga yang tercermin dari tingkat tabungan dan tingkat pinjaman, yang berdampak pada tingginya tingkat distress (Musdholifah et al., 2013). Perkembangan inflasi dapat diukur dengan indikator IHK. Rumus yang digunakan untuk menghitung laju inflasi berdasarkan penelitian dari Prianti \& Musdholifah (2018) pada persamaan (14).

Laju Inflasi ${ }_{t}=\frac{\text { IHK }_{t}-\text { IHK }_{t-1}}{\mathrm{IHK}_{t-1}} X 100 \%$

\section{Nilai Tukar}

Nilai tukar merupakan nilai yang digunakan untuk menukarkan barang dan jasa dari suatu negara ke negara lain, pergerakan nilai tukar yang melemah dapat mengakibatkan kondisi bank bermasalah yaitu depresiasi (Budiarti, 2014). Nilai tukar dihitung menurut penelitian dari Darmawan (2017) pada persamaan (15).

Nilai Tukar $=\frac{\text { Kurs Jual+Kurs Beli }}{2}$ X 100\% 
Wanda Hamidatun Nisak. Pengaruh Rasio RGEC, Bank Size, Market Value, serta Variabel Makro Ekonomi terhadap Prediksi Financial Distress Menggunakan CD-Index

\section{Hubungan Antar Variabel}

Berdasarkan teori generasi kedua, banyaknya dana yang ditarik oleh nasabah akibat adanya asimetri informasi menyebabkan kegagalan dalam penyaluran dana dalam aktiva produktif hal ini sebagai penyebab naiknya kredit macet atau rasio NPL (Prianti \& Musdholifah, 2018). Kondisi ini menyebabkan perusahaan memberikan sinyal buruk kepada pihak eksternal (Kuncoro \& Agustina, 2017). Pernyataan ini sejalan dengan penelitian dari Haq \& Harto (2019) dan Mayes \& Stremmel (2014).

H1: Ada pengaruh variabel NPL terhadap financial distress pada BUSN.

Rasio LDR dapat didefinisikan sebagai kemampuan yang dimiliki bank dalam memenuhi penyaluran kredit dengan aset produktif (Rahmaniah \& Wibowo, 2015). Berdasarkan teori generasi kedua, penarikan secara besar-besaran yang dilakukan nasabah menyebabkan dana yang dihimpun bank semakin sedikit, sehingga aset yang digunakan untuk berjaga-jaga juga sedikit. Penelitian dari Musdholifah et al. (2013) menyatakan nilai LDR yang tinggi memungkinkan mengalami krisis perbankan karena ketika bank mendapatkan pinjaman dengan return yang tinggi dapat diindikasikan bahwa pendapatan bank berasal dari pinjaman yang berisiko tinggi. Hasil ini didukung oleh Theodorus \& Artini (2018), Hamida et al. (2017), Kurniasari \& Ghozali (2013), dan Musdholifah et al. (2020).

H2: Ada pengaruh variabel LDR terhadap financial distress pada BUSN.

Dewan direksi dapat diartikan sebagai organ dalam penentuan kebijakan dan strategi yang tepat (Prianti \& Musdholifah, 2018). Teori generasi kedua menyatakan bahwa adanya asimetri informasi menyebabkan nasabah melakukan penarikan dananya, peran dewan direksi adalah mengendalikan manajemen bank dengan berbagai kebijakan agar kondisi bank tidak semakin memburuk (Prianti \& Musdholifah, 2018). Besarnya ukuran dewan direksi dapat memermudah proses monitor dan efektifnya pelaporan keuangan (Hanifah \& Purwanto, 2013). Ukuran dewan direksi yang besar dapat memerkecil probabilitas terjadinya financial distress karena pengawasan yang lebih kompleks. Pernyataan ini didukung oleh Rahmawati \& Khoiruddin (2017).

H3: Ada pengaruh variabel ukuran dewan direksi terhadap financial distress pada BUSN.

ROA didefinisikan sebagai kemampuan pengelolaan aset yang dimiliki bank dalam mendapatkan keuntungan (Haq \& Harto, 2019). Teori generasi kedua yang mengatakan bahwa penarikan yang dilakukan nasabah secara besar-besaran menyebabkan dana yang dikelola bank semakin sedikit, akibatnya laba yang dihasilkan juga semakin sedikit. Menurut Sofiasani \& Gautama (2016) bahwa semakin tinggi nilai ROA mengindikasikan bank mampu dalam pengelolaan aset secara baik dan benar sehingga memeroleh keuntungan optimal. Pernyataan ini didukung oleh Theodorus \& Artini (2018), Andari \& Wiksuana (2017), dan Budiarti (2014).

H4: Ada pengaruh variabel ROA terhadap financial distress pada BUSN.

Rasio ROE didefinisikan sebagai penilaian kesehatan bank yang dilihat dari pengelolaan modal dalam mendapatkan laba (Kasmir, 2014:328). Teori generasi kedua menjelaskan kepanikan yang dihadapi nasabah terhadap dana yang disimpan menyebabkan pengelolaan terhadap modal sendiri juga semakin lemah, akibatnya laba yang dihasilkan juga mengalami penurunan (Prianti \& Musdholifah, 2018). Ketidakmampuan bank dalam mendapatkan serta memertahankan keuntungan menyebabkan kerugian bank dan berdampak buruk pada kualitas aset dan tingkat permodalan bank, sehingga meningkatkan kemungkinan terjadinya financial distress (Mayes \& Stremmel, 2014). Pernyataan ini didukung oleh Shidiq \& Wibowo (2017) dan Wulandari et al. (2017).

H5: Ada pengaruh variabel ROE terhadap financial distress pada BUSN. 
Rasio NIM didefinisikan sebagai pengelolaan aktiva produktif untuk mendapatkan bunga.bersih Pengelolaan ini dapat berupa surat hutang, penyertaan pada saham, dan kredit yang lancar Prianti \& Musdholifah (2018). Model generasi kedua dapat diterapkan dalam rasio NIM, ketika nasabah merasa cemas terhadap dana yang disimpan maka akan segara menarik dananya, karena takut jika dananya tidak dapat kembali. Semakin besar nilai NIM maka peluang mengalami kondisi financial distress semakin kecil, karena pendapatan bunga diterima bank atas pengelolaan aset produktif semakin besar yaitu dengan menjalankan fungsi intermediasi (Sadida, 2018; Bestari \& Rohman, 2013). Pernyataan ini didukung oleh Hamida et al. (2017) dan Shidiq \& Wibowo (2017).

H6: Ada pengaruh variabel NIM terhadap financial distress pada BUSN.

Rasio ini digunakan sebagai alat untuk mengukur kesehatan perbankan yang dilihat dari kemampuan dan tingkat efisiensi bank dalam melakukan kegiatan operasional (Siregar \& Fauzie, 2012). Berdasarkan teori generasi kedua, kepanikan yang dialami nasabah menyebabkan bank terhambat dalam melaksanakan operasionalnya, akibatnya beban yang ditanggung lebih besar jika dibandingkan pendapatan operasionalnya, atau nilai rasio BOPO tinggi (Prianti \& Musdholifah, 2018). Beban yang besar menandakan bahwa bank kesulitan keuangan, kondisi ini dapat memperburuk reputasi bank di mata masyarakat Pernyataan ini sejalan dengan penelitian dari Theodorus \& Artini (2018) dan Sofiasani \& Gautama (2016).

H7: Ada pengaruh variabel BOPO terhadap financial distress pada BUSN.

Rasio CAR menggambarkan kemampuan bank dalam memertahankan modal dan kesanggupan pihak manajemen melakukan pengawasan, pengukuran, dan pengontrolan risiko yang dapat memengaruhi modal inti serta pelengkap (Kuncoro \& Agustina, 2017). Berdasarkan teori generasi kedua, kepanikan yang dihadapi nasabah akan menurunkan cadangan modal untuk melindungi aset yang berisiko atau nilai CAR rendah (Prianti \& Musdholifah, 2018). Menurut Bestari \& Rohman (2013) semakin rendah CAR menandakan modal bank juga kecil, sehingga berpeluang mengalami kondisi bermasalah. Pendapat ini sejalan dengan penelitian dari Sadida (2018) dan Shidiq \& Wibowo (2017).

H8: Ada pengaruh variabel CAR terhadap financial distress pada BUSN.

Besar kecilnya bank dapat dilihat dari banyaknya aset, aset yang baik mampu meminimalkan risiko terjadinya financial distress pada bank (Bestari \& Rohman, 2013). Total aset yang dimiliki oleh bank dapat menunjukkan kemampuan bank dalam pendanaan investasi serta perluasan pangsa pasar sehingga mempunyai prospek cukup baik di masa yang akan datang (Putri, 2018). Menurut teori generasi kedua penarikan secara besar-besaran akan menyebabkan aset yang dimiliki oleh bank mengalami penurunan, apabila aset yang tersedia tidak dikelola secara maksimal akan menimbulkan kondisi yang bermasalah. Sejalan dengan Bestari \& Rohman (2013) dan Baselga-pascual et al. (2015).

H9: Ada pengaruh variabel bank size terhadap financial distress pada BUSN.

Rasio PBV dirumuskan sebagai berapa banyak rupiah yang harus dibayar investor terkait dengan setiap rupiah nilai buku per lembar saham investor di dalam perusahaan untuk mendapatkan suatu keuntungan (Purwohandoko, 2009:48). Variabel PBV dapat dijelaskan dengan teori generasi pertama. Lemahnya kondisi ekonomi negara menyebabkan perekonomian secara keseluruhan ikut melemah, kondisi ini menyebabkan investor akan menjual sahamnya, dan harga saham perbankan bergerak turun. Sebaliknya ketika perekonomian meningkat maka PBV akan bergerak naik (Kuncoro \& Agustina, 2017). Penelitian dari Choirina \& Yuyetta (2015) bahwa PBV tinggi dapat meningkatkan kepercayaan kepada pasar mengenai performa perbankan, tidak hanya kinerja bank pada saat ini tetapi juga prospek kinerja bank di masa yang akan datang.

H10: Ada pengaruh variabel PBV terhadap financial distress pada BUSN. 
Wanda Hamidatun Nisak. Pengaruh Rasio RGEC, Bank Size, Market Value, serta Variabel Makro Ekonomi terhadap Prediksi Financial Distress Menggunakan CD-Index

PER adalah rasio yang menujukan kemampuan investor dalam membayar saham agar mendapatkan keuntungan per lembar saham dalam periode berjalan (Purwohandoko, 2009:48). Variabel PER dapat dijelaskan dengan teori generasi pertama. Lemahnya perekonomian suatu negara menyebabkan investor akan menjual sahamnya karena takut return yang dihasilkan tidak sesuai dengan ekspektasi, ketika investor banyak yang menjual saham maka harga saham perbankan tersebut akan bergerak menurun, kondisi ini menunjukkan bahwa nilai rasio PER rendah, pernyataan ini sejalan dengan hasil penelitian dari Gunsel (2012).

H11: Ada pengaruh variabel PER terhadap financial distress pada BUSN.

Banyaknya barang dan jasa didalam suatu negara digunakan sebagai alat ukur pertumbuhan ekonomi (Tandelilin, 2010:342). GDP adalah salah satu indikator dari faktor eksternal yang memengaruhi terjadinya kondisi financial distress. Ketika perekonomian negara mengalami penurunan maka banyak sektor yang terdampak dari kondisi ini, baik perusahaan maupun perbankan, perolehan investasi asing banyak yang ditarik sehingga jumlah net foreign direct investment yang ada di Indonesia bernilai negatif (Prianti \& Musdholifah, 2018). Kondisi ini sesuai dengan teori generasi pertama, yang menyebabkan mata uang domestik melemah, dan probabilitas mengalami financial distress semakin besar, pernyataan tersebut sejalan dengan penelitian dari (Shidiq \& Wibowo, 2017; Baselga-pascual et al., 2015).

H12: Ada pengaruh antara variabel GDP terhadap financial distress pada BUSN.

Inflasi didefinisikan sebagai peningkatan harga-harga barang yang berlaku secara keseluruhan dalam suatu perekonomian (Tandelilin, 2010:342). Mahmood et al. (2014) melakukan krisis perbankan Pakistan yang mendapatkan hasil jika inflasi berpengaruh terhadap prediksi financial distress, hal ini karena ketika inflasi dalam negara meningkat dan berkesinambungan maka memberikan pengaruh positif pada investasi yang terjadi dalam suatu negara tersebut. Penelitian ini didukung riset dari Musdholifah et al. (2013) yang menemukan hasil hubungan antara inflasi dengan financial distress. Hasil riset menunjukkan peningkatan inflasi berkaitan dengan naiknya suku bunga, hal tersebut dapat memberikan dampak negatif khususnya pada sistem perbankan, keadaan ini sesuai dengan yang dijelaskan dalam teori generasi pertama.

H13: Ada pengaruh variabel inflasi terhadap financial distress pada BUSN.

Nilai tukar merupakan nilai yang digunakan untuk kegiatan pertukaran barang dan jasa dengan negara lain (Budiarti, 2014). Turunnya cadangan devisa ditandai dengan lemahnya mata uang rupiah terhadap asing, kondisi ini sesuai dengan yang dijelaskan dalam teori generasi pertama, yaitu krisis perbankan terjadi karena faktor fundamental negara yang bersangkutan. Pernyataan ini sejalan dengan Budiarti (2014) bahwa nilai tukar memiliki pengaruh terhadap financial distress, tingginya depresiasi nilai tukar akan meningkatkan kewajiban luar negeri untuk terdenominasinya mata uang rupiah, sehingga menurunkan kemampuan bank memenuhi kewajibannya.

H14: Ada pengaruh variabel nilai tukar terhadap financial distress pada BUSN.

\section{METODE PENELITIAN}

Jenis penelitian termasuk kedalam penelitian asosiatif, metode kuantitatif. Sedangkan sumber datanya yaitu data sekunder. Pada penelitian ini, variabel yang digunakan dari faktor internal bank terdiri dari rasio LDR, NPL, GCG, ROA, ROE, NIM, BOPO, CAR, dan bank size yang diperoleh dari hasil perhitungan angka di neraca dan laporan rugi laba pada laporan tahunan yang terpublikasi di website idx dan website resmi perbankan. Sedangkan variabel market value yang diproksikan dengan PBV dan PER serta variabel makro ekonomi yang diproksikan dengan GDP, inflasi, dan nilai tukar diperoleh dari website resmi BI dan BPS. Populasi yang digunakan adalah seluruh perbankan kelompok BUSN periode 2015-2019. Teknik sampling menggunakan purposive sampling dengan kriteria adalah (1) BUSN terdaftar pada Otoritas Jasa Keuangan, (2) laporan tahunan diterbitkan 
selama periode 2015-2019, (3) BUSN tidak mengadakan merger maupun akuisisi dalam periode 2015-2019, (4) menyediakan data sebagai variabel dalam penelitian. Jumlah sampel yang didapatkan sebanyak 19 bank. Model regresi logistik sebagai teknik analisis data, binary logistic merupakan teknik analisis yang memiliki dua hasil kategori untuk variabel dependenya. Menurut Ghozali (2018), langkah yang dilakukan untuk analisis regresi logistik adalah menilai model fit dengan melihat Nagelkerke's $R$ square pada multiple regression. Langkah selanjutnya adalah menguji hipotesis nol bahwa data harus empiris dengan model menggunakan Hosmer and Limeshow's Goodness of Fit Test. Estimasi parameter dan ketepatannya dapat dilihat dari output SPSS pada tabel variable in equation. Financial distress sebagai variabel dependen yang dikelompokan menjadi dua kategori yaitu kategori distress dengan skor 1 dan skor 0 untuk bank yang non distress.

\section{HASIL DAN PEMBAHASAN}

\section{Financial Distress}

Jumlah bank yang diprediksi mengalami financial distress pada tahun 2015 berjumlah 8 bank, kemudian meningkat ditahun 2016 sebesar 10 bank. Pada tahun berikutnya yaitu tahun 2017 dan 2018 masing-masing sebesar 9 bank yang diprediksi mengalami distress. Tahun 2019 kembali meningkat sebesar 10 bank yang diprediksi mengalami distress dari 19 sampel penelitian.

\section{Menilai Model Fit}

Nilai -2 log likelihood sebesar 131.603.yaitu nilai yang memasukkan konstanta saja. Nilai $-2 \log$ likelihood turun menjadi 125.917 ketika memasukkan variabel independen. Jadi variabel independen yang dimasukkan dalam model lebih baik dibandingkan dengan menggunakan konstanta saja. Sehingga penelitian ini fit dengan data atau H0 diterima.

\section{Koefisien Determinasi}

Nilai nagelkerke's $R$ square sebesar 7,7\% artinya variabel independen yaitu NPL, LDR, ukuran dewan direksi, ROA, ROE, BOPO, NIM, CAR, bank size, PBV PER, GDP, inflasi, dan nilai tukar mampu menjelaskan terjadinya financial distress, sedangkan 92,3\% dijelaskan oleh variabel lain di luar penelitian yang dapat memengaruhi kebangkrutan.

\section{Uji Kelayakan Model}

Pengujian hosmer and limeshow test dalam penelitian ini sebesar 0,340 (hosmer and limeshow test $>0,05$ ) artinya hipotesis Nol diterima karena model prediksi sesuai dengan data observasinya, maka pengujian hipotesis dapat dilakukan.

\section{Uji Keakuratan Regresi}

Model prediksi terjadinya financial distress menggunakan CD Indeks mempunyai tingkat akurasi relatif tepat yaitu $58,9 \%$

\section{Pengujian Hipotesis}

\section{Tabel 1.}

\section{HASIL PENGUJIAN HIPOTESIS}

\begin{tabular}{|c|c|c|c|c|c|c|c|}
\hline \multicolumn{8}{|c|}{ Variables in the Equation } \\
\hline & & B & S.E. & Wald & Df & Sig. & $\operatorname{Exp}(B)$ \\
\hline \multirow[t]{2}{*}{ Step $1^{\mathrm{a}}$} & PBV & -.546 & .247 & 4.890 & 1 & .027 & .579 \\
\hline & Constant & .679 & .386 & 3.100 & 1 & .078 & 1.972 \\
\hline
\end{tabular}

Sumber: Output SPSS (2021, data diolah)

Hasil tabel 1 menunjukkan bahwa variabel bebas yang signifikan yaitu PBV dengan nilai signifikan negatif, persamaan regresi untuk penelitian ini terdapat pada persamaan (16). 
Wanda Hamidatun Nisak. Pengaruh Rasio RGEC, Bank Size, Market Value, serta Variabel Makro Ekonomi terhadap Prediksi Financial Distress Menggunakan CD-Index

$\operatorname{Ln} \frac{p}{1-p}=-0,546 P B V$

Keterangan:

$\mathrm{p} \quad=$ Financial Distress

PBV =Price to Book Value

\section{Pengaruh NPL terhadap Financial Distress}

Variabel risk profile yang diukur dengan NPL tidak bisa memprediksi financial distress pada perbankan, kondisi ini tidak sejalan dengan teori yang dijelaskan oleh Obstfeld (1986) bahwa krisis disebabkan faktor internal perbankan (self-fulfilling prophency). Tidak adanya hubungan ini karena kredit yang tersalurkan hanya kepada masyarakat sedangkan perbankan juga menyalurkan dananya kepada bank-bank yang membutuhkan dana (Prianti \& Musdholifah, 2018). Financial distress pada perbankan tidak hanya berasal dari tingginya NPL tetapi pihak manajemen dapat melihat rasio lainnya. Misalnya pada Bank Harda International nilai NPL yang didapatkan pada tahun 2019 sebesar $10,16 \%$ yang melebihi batas yang dianjurkan Bank Indonesia, namun pada tahun tersebut bank diprediksi tidak dalam kondisi distress karena rasio CAR yang tinggi sebesar 16,20\% (> 8\%) sehingga mampu menutup kerugian dengan modal yang dimilikinya dan rasio NIM sebesar $4,21 \%$ (> $1,5 \%)$ sehingga Bank Harda International dapat menutupi permasalahan kredit macet. Tidak adanya hubungan NPL dengan prediksi financial distress didukung penelitian dari Musdholifah et al. (2020), Sadida (2018), dan Kurniasari \& Ghozali (2013).

\section{Pengaruh LDR terhadap Financial Distress}

Variabel risk profile yang diukur dengan LDR tidak bisa memprediksi financial distress pada BUSN. Hal ini tidak sejalan dengan teori generasi kedua bahwa krisis yang terjadi pada bank akibat selffulfilling prophency. Tidak adanya pengaruh ini sejalan dengan Andari \& Wiksuana (2017) bahwa rasio LDR memiliki hubungan dengan keuntungan bank dalam penyaluran kredit. Pendapatan bunga yang tinggi berasal dari banyaknya kredit yang disalurkan sehingga peluang distress kecil. Namun tingginya LDR menandakan bahwa bank tidak mampu memenuhi pinjaman pada saat jatuh tempo. Berdasarkan data ini tidak ditemukan perbedaan yang spesifik LDR bank yang prediksi terjadi financial distress dan bank yang sehat, misalnya Bank QNB yang memiliki nilai LDR pada tahun 2015 sebesar 112,54\% (> 85\%) tetapi berdasarkan perhitungan CD Indeks bank QNB tidak diprediksi mengalami financial distress, berbeda dengan Bank Artha Graha yang memiliki nilai LDR 80,75\% (< 85\%) diprediksi mengalami financial distress pada tahun tersebut. Sehingga semakin besar nilai LDR tidak bisa memprediksi financial distress. pernyataan ini sejalan Sadida (2018), Betz et al. (2014) dan Shidiq \& Wibowo (2017).

\section{Pengaruh Ukuran Dewan Direksi terhadap Financial Distress}

Good corporate governance diproksikan dengan banyaknya dewan direksi tidak mampu memprediksi financial distress pada kelompok Bank Umum Swasta Nasional, dan menolak hipotesis penelitian. Hasil ini sesuai dengan Sadida (2018) jumlah dewan direksi tidak selalu mengalami peningkatan secara signifikan setiap tahunnya. Banyaknya dewan direksi tidak dapat diukur pengaruhnya dengan financial distress. Misalnya Bank Permata selalu mengalami penurunan jumlah dewan direksi, tahun 2016 jumlah dewan direksi berjumlah 10 orang, kemudian turun di tahun 2017 dan 2018 masingmasing 9 dan 8 orang. Berbeda dengan bank CIMB Niaga yang mengalami peningkatan di tahun 2015 jumlah dewan direksi 9 orang, kemudian meningkat di tahun 2016 dan 2017 masing-masing berjumlah 10 orang. Pernyataan ini sejalan dengan Haq \& Harto (2019) dan Sadida (2018).

\section{Pengaruh ROA terhadap Financial Distress}

Variabel earning yang diukur dengan ROA tidak berpengaruh dalam prediksi financial distress pada perbankan BUSN, yang menolak hipotesis bahwa adanya hubungan yang signifikan ROA dengan kebangkrutan. Menurut Haq \& Harto (2019) yang menyatakan semakin tinggi nilai ROA mengindikasikan bahwa bank mampu dalam pengelolaan aset secara baik dan benar, hal ini akan memeroleh keuntungan optimal. Namun pendapat ini ditolak karena hasil penelitian menunjukkan bahwa nilai mean lebih rendah daripada standar deviasi ROA, yaitu 0,5771 < 1,91877. Hal ini 
menunjukkan bahwa variabel earning yang diukur dengan rasio ROA menghasilkan kesenjangan antara nilai maksimal dan minimal terlalu jauh, akibatnya ada pengaruh hasil uji hipotesisnya. Hal ini sesuai penelitian Sadida (2018), Bestari \& Rohman (2013), dan Siregar \& Fauzie (2012).

\section{Pengaruh ROE terhadap Financial Distress}

Variabel earning yang diukur dengan ROE tidak berpengaruh dalam memprediksi financial distress, yang menolak hipotesis penelitian. Hasil ini juga menolak teori generasi kedua, bahwa faktor internal dapat menyebabkan terjadinya krisis, seperti penarikan dana oleh nasabah (bank runs), menyebabkan pengelolaan atas modal sendiri juga semakin lemah. Tidak adanya pengaruh antara rasio ROE dengan prediksi financial distress karena tingginya perolehan laba dapat meningkatkan jumlah kewajiban minimum, apabila kondisi ini tidak diatasi maka menganggu kesehatah bank untuk melakukan ekspansif dalam kegiatan operasional karena harus menyediakan modal minimum yang tertalu besar (Pristanti \& Musdholifah, 2020). Contohnya pada Bank QNB Indonesia nilai rasio ROE pada tahun 2017 bernilai negatif 26,95\% tetapi menurut perhitungan CD Indeks Bank QNB Indonesia tidak mengalami financial distress karena didukung oleh nilai rasio NPL yang rendah sebesar $1,85 \%$ (>8\%), artinya Bank QNB Indonesia mampu mengelola kredit yang disalurkan dengan baik yang dibuktikan dengan nilai rasio kredit macet yang rendah. Hasil ini sesuai dengan Siregar \& Fauzie (2012), Kurniasari \& Ghozali (2013), dan Messai \& Gallali (2015)

\section{Pengaruh NIM terhadap Financial Distress}

Variabel earning yang diukur dengan NIM tidak bisa mendeteksi financial distress pada BUSN, rasio NIM dijelaskan dengan teori generasi kedua bahwa krisis terjadi karena adanya asimetri informasi yang menyebabkan kecemasan nasabah terhadap dana yang disimpan, kondisi ini membuat nasabah menarik uangnya dan bank akan memperoleh sedikit laba yang berasal dari bunga simpanan. Namun hasil ini sejalan dengan penelitian dari Prianti \& Musdholifah (2018) bahwa rasio NIM yang tidak signifikan ini dapat dikaitkan dengan CD Indeks sebagai metode dalam perhitungan financial distress pada bank. Besarnya risiko suku bunga dan nilai tukar yang merupakan elemen dalam CDI memengaruhi kesehatan bank, akibatnya besarnya NIM tidak bisa digunakan dalam prediksi financial distress pada bank. Hal ini sesuai dengan Siregar \& Fauzie (2012) dan Betz et al. (2014).

\section{Pengaruh BOPO terhadap Financial Distress}

Variabel earning diukur dengan BOPO tidak mampu mendeteksi financial distress, serta menolak teori generasi kedua dan hipotesis penelitian. Semakin kecil nilai BOPO artinya bank mampu dalam menekan biaya operasionalnya sehingga meminimalkan terjadinya financial distress (Sofiasani \& Gautama, 2016). Hasil ini sejalan Prianti \& Musdholifah (2018) nilai BOPO yang tinggi dapat menyebabkan bank mengalami distress, karena kecilnya nilai pinjaman pihak asing. Jumlah hutang luar negeri yang rendah mengakibatkan kecilnya risiko nilai tukar, berpengaruh pada nilai variabel terikat dalam perhitungan CDI yang kecil dan bank diprediksi tidak terjadi financial distress. hal ini sesuai dengan Bestari \& Rohman (2013), Kurniasari \& Ghozali (2013) dan, Siregar \& Fauzie (2012).

\section{Pengaruh CAR terhadap Financial Distress}

Variabel Capital diukur dengan CAR tidak berpengaruh signifikan dalam prediksi financial distress pada kelompok bank umum swasta nasional, dan tidak mendukung teori generasi kedua serta hipotesis yang diajukan. Hasil ini juga menolak penelitian dari Mayes \& Stremmel (2014), bahwa semakin rendah nilai permodalan bank akan meningkatkan peluang terjadinya financial distress. Adanya merger maupun akuisisi dapat meningkatkan susunan permodalan pada bank yang mengalami gangguang pada tingkat likuiditas sebagai salah satu upaya agar tidak mengalami krisis. Ketika bank mengalami kerugian tetapi struktur permodalan tetap kuat dengan melakukan berbagai kebijakan hutang, maka bank diprediksi tidak mengalami kebangkrutan karena tingginya nilai CAR. Sehingga variabel CAR belum bisa dalam memprediksi financial distress. Hasil penelitian ini didukung oleh Bestari \& Rohman (2013), Siregar \& Fauzie (2012), dan Haq \& Harto (2019). 
Wanda Hamidatun Nisak. Pengaruh Rasio RGEC, Bank Size, Market Value, serta Variabel Makro Ekonomi terhadap Prediksi Financial Distress Menggunakan CD-Index

\section{Pengaruh Bank Size terhadap prediksi Financial Distress}

Variabel ukuran bank dapat dihitung dari banyaknya aset, hasil penelitian ini menunjukkan bahwa tidak adanya hubungan dengan financial distress. Hasil ini menolak teori yang dikemukakan oleh Obstfeld (1986) dan Bestari \& Rohman (2013) yang mengemukakan semakin besar ukuran bank maka meningkatkan kepercayaan nasabah dan investor untuk menanamkan dananya, dan bank akan terhindar dari kondisi yang bermasalah. Namun penelitian ini sejalan dengan hasil temuan dari Theodorus \& Artini (2018), bahwa kegagalan bank tidak hanya diprediksi dari banyaknya aset bank yang bersangkutan tetapi perbankan juga harus mengoptimalkan sumber daya lainnya agar kebutuhan yang berhubungan dengan investasi dapat segera dipenuhi.

\section{Pengaruh PBV terhadap Prediksi Financial Distress}

Variabel market value diproksikan dengan PBV berpengaruh signifikan negatif terhadap financial distress, yang menerima hipotesis penelitian. Hasil ini dapat dijelaskan teori generasi pertama adanya ketidakstabilan perekonomian negara menyebabkan investor akan menjual sahamnya, kondisi ini menyebabkan harga saham bergerak turun dan PBV bank yang bersangkutan akan rendah. Hal ini juga sejalan dengan penelitian dari Choirina \& Yuyetta (2015) bahwa meningkatnya nilai PBV memberikan kepercayaan kepada pasar mengenai harapan perbankan kedepannya, tidak hanya kinerja bank pada saat ini tetapi juga prospek kinerja bank di masa yang akan datang. Dengan PBV yang tinggi bank akan terhindar dari financial distress.

\section{Pengaruh PER terhadap Prediksi Financial Distress}

Variabel market value yang diproksikan dengan PER mendapatkan hasil bahwa tidak adanya hubungan dengan prediksi financial distress pada perbankan kelompok BUSN. Hasil ini menolak teori generasi pertama dan hipotesis yang diajukan bahwa PER dapat digunakan sebagai alat prediksi financial distress. Hasil ini menunjukkan nilai mean lebih kecil daripada standar deviasinya yang artinya nilai maksimun dan minimum terlalu jauh sehingga adanya pengaruh terhadap uji hasil hipotesisnya. Sejalan dengan hasil penelitian dari Kuncoro \& Agustina (2017) nilai PER yang tinggi belum tentu mencerminkan baiknya kinerja bank, penurunan rata-rata pertumbuhan laba perbankan juga terlihat dari rasio PER yang tinggi.

\section{Pengaruh GDP terhadap Prediksi Financial Distress}

Variabel makroekonomi yang diukur dengan GDP tidak bisa digunakan dalam prediksi financial distress pada BUSN, menolak teori krisis generasi pertama bahwa lemahnya pertumbuhan ekonomi akan diikuti dengan lemahnya aktivitas perekonomian suatu negara baik dari sektor keuangan maupun riil sehingga probabilitas mengalami financial distress akan meningkat (Wulandari et al., 2017). Adanya perubahan pada perekonomian akan memberikan pengaruh terhadap keputusan industri yang selanjutnya dapat memberikan pengaruh kepada perbankan dan pihak internal akan menyesuaikan perubahan dari perekonomian yang terjadi. Pemerintah juga mengeluarkan kebijakan untuk menstimulus pertumbuhan GDP, agar sektor perbankan dapat terselamatkan dari krisis, misalnya menurunkan suku bunga acuan, menurunkan batas cadangan untuk mewujudkan efek multiplier (Prianti \& Musdholifah,2018). Hasil ini sesuai dengan Musdholifah et al. (2020).

\section{Pengaruh Inflasi terhadap Prediksi Financial Distress}

Variabel makroekonomi yang diukur dengan inflasi tidak bisa digunakan dalam prediksi financial distress, menolak hipotesis penelitian dan teori generasi pertama bahwa laju inflasi berpengaruh terhadap prediksi financial distress pada sektor perbankan. Meningkatnya laju inflasi akan diikuti oleh kenaikan tingkat suku bunga, sehingga risiko gagal bayar akan tinggi dan bank akan mengalami kegagalan (Mahmood et al., 2014). Faktor fundamental perbankan selalu diterapkan dalam penyesuaian kondisi ekonomi misalnya menurunkan suku bunga pinjaman untuk meningkatkan terjadinya investasi belum bisa memengaruhi financial distress pada perbankan yang dihitung dengan menggunakan CD Indeks. Hasil ini sesuai dengan Musdholifah et al. (2020) dan Betz et al. (2014).

\section{Pengaruh Nilai Tukar terhadap Prediksi Financial Distress}

Variabel makro ekonomi yang diukur dengan nilai tukar tidak mampu memprediksi financial distress pada perbankan, menolak teori krisis generasi pertama dan hipotesis yang diajukan, Budiarti (2014) 
mengemukakan adanya pengaruh nilai tukar terhadap financial distress, nilai tukar yang terdepresiasi meningkatkan hutang luar negeri bank untuk terdenominasinya nilai rupiah, sehingga menurunkan kemampuan bank untuk memenuhi kewajibannya. Tidak adanya hubungan ini karena adanya kebijakan hedging yang dilakukan oleh Bank Indonesia untuk melindungi nilai tukar mata uang domestik terhadap mata uang lain sehingga adanya fluktuasi tidak memengaruhi aset yang dimiliki bank. Hasil ini sesuai dengan Musdholifah et al. (2020) dan Wulandari et al. (2017).

\section{KESIMPULAN}

Sesuai dengan hasil analisis data maka kesimpulan yang dapat ditarik yaitu pada variabel internal yang dijelaskan dengan teori krisis generasi kedua tidak ada yang berpengaruh terhadap prediksi financial distress pada perbankan, karena respon perbankan sangat baik, disatu sisi lemahnya salah satu variabel internal akan ditutupi oleh variabel internal yang lain sehingga bank akan terhindar dari terjadinya financial distress. Namun variabel market value yang diproksikan dengan PBV memiliki pengaruh secara negatif dalam memprediksi financial distress pada perbankan, hal ini menyebabkan pihak internal tetap memantau perkembangan pasar agar harga saham tidak bergerak turun. Sedangkan variabel PER dan makro ekonomi tidak bisa digunakan dalam memprediksi financial distress, karena kuatnya faktor fundamental bank dalam menghadapi kondisi perkonomian.

Hasil ini masih memiliki keterbatasan seperti objek dan periode pengamatan, sehingga belum bisa memprediksi financial distress pada BUSN. Kekuatan hubungan variabel bebas sebesar 7,7\% artinya masih banyak faktor lain yang dapat memprediksi financial distress. Saran untuk peneliti selanjutnya dengan menggunakan tambahan variabel bebas yang mampu memprediksi financial distress, seperti faktor internal, faktor pasar, makro ekonomi, faktor global dan masih banyak lagi variabel yang berhubungan dengan institusional agar hubungan antara variabel bebas dengan variabel terikat dapat lebih kuat dan menambah tingkat keakurasian model dalam memprediksi terjadinya financial distress pada perbankan. Karena banyaknya hal yang tidak berpengaruh maka bank harus tetap mempertahankan faktor internal dan eksternal agar fumdamental perbankan tetap kuat dan terhindar dari financial distress.

\section{DAFTAR PUSTAKA}

Andari, N. M. M., \& Wiksuana, I. G. B. (2017). RGEC sebagai Determinasi dalam Menanggulangi Financial Distress pada Perusahaan Perbankan di Bursa Efek Indonesia. E-Jurnal Manajemen Unud, 6 (1), 116-145.

Bank Indonesia (2011). Surat Edaran Bank Umum Konvensional di Indonesia Perihal Penilaian Tingkat Kesehatan Bank Umum, (Online), (www.bi.go.id., diakses pada tanggal 5 Januari 2021).

Baselga, L., Trujillo, A., \& Cardone, C. (2015). North American Journal of Economics and Finance Factors influencing bank risk in Europe : Evidence from the financial crisis. North American Journal of Economics and Finance, 34, 138-166. https://doi.org/10.1016/j.najef.2015.08.004.

Berita, S. (2018). Bank Kian Solid. Beritasatu.Com. https://www.beritasatu.com/tajuk/6232/bankkian-solid (diakses pada tanggal 16 Desember 2020).

Bestari, A. R., \& Rohman, A. (2013). Pengaruh Rasio Camel dan Ukuran Bank terhadap Prediksi Kondisi Bermasalah pada Sektor Perbankan (Studi Pada Perusahaan Perbankan yang Terdaftar di Bursa Efek Indonesia Tahun 2007 - 2011). Diponegoro Journal of Accounting, 2(3), 1-9.

Betz, F., Peltonen, T. A., Sarlin, P., \& Oprica, S. (2014). Predicting distress in European banks. Journal of Banking \& Finance, 45, 225-241. https://doi.org/10.1016/j.jbankfin.2013.11.041. 
Wanda Hamidatun Nisak. Pengaruh Rasio RGEC, Bank Size, Market Value, serta Variabel Makro Ekonomi terhadap Prediksi Financial Distress Menggunakan CD-Index

Budiarti, W. (2014). Identifikasi Modal, Profitabilitas, Likuiditas, PDB, Inflasi dan Nilai Tukar Sebagai Prediksi Krisis Perbankan di Indonesia. Jurnal Ilmu Manajemen, 2(4), 1208-1221.

Budisantoso, T., \& Nuritomo. (2018). Bank dan Lembaga Keuangan Lain (3rd ed.). Jakarta Selatan: Salemba Empat.

Choirina, P. M., \& Yuyetta, E. N. A. (2015). Analisis Faktor-Faktor yang Memengaruhi Probabilitas Financial Distress Perbankan Indonesia. Diponegoro Journal of Accounting, 4(2), 1-9.

Darmawan, S. (2017). Analisis Pengaruh Corporate Governance, Variabel Ekonomi Makro terhadap Financial Distress dengan Variabel Kontrol Ukuran Perusahaan dan Jenis Kepemilikan. Jurnal Bisnis dan Teknologi Informasi, 7(1), 100-122.

Financedetik. (2009, April 15). Kronologi dan Latar Belakang Krisis Financial Global. Finance.Detik.Com. https://www.kompas.com/skola/read/2020/02/10/170000769/penyebabkrisis-moneter-di-indonesia?page=all\#page1 (diakses pada tanggal 3 Januari 2021).

Ghozali, I. (2018). Aplikasi Analisis Multivariate dengan Program IBM SPSS 25 (9th ed.). Semarang: Badan Penerbit Undip.

Gischa, S. (2020, February 10). Penyebab Krisis Moneter di Indonesia. Kompas.Com. https://www.kompas.com/skola/read/2020/02/10/170000769/penyebab-krisis-moneter-diindonesia?page=all (diakses pada tanggal 3 Januari 2021).

Gunsel, N. (2012). Micro and macro determinants of bank fragility in North Cyprus economy. African Journal of Business Management, 6(4), 1323-1329. https://doi.org/10.5897/AJBM11.1055.

Hamida, D., Ahmar, N., \& Djaddang, S. (2017). Determinasi Prediksi Krisis Perbankan Berbasis Banking Sector Fragility Index. Jurnal Ilmiah Akuntansi Fakultas Ekonomi, 3(2), 1-16.

Hanifah, O. E., \& Purwanto, A. (2013). Pengaruh Struktur Corporate Governance dan Financial Indicators terhadap Kondisi Financial. Diponegoro Journal of Accounting, 2(2), 1-15.

Haq, H. I., \& Harto, P. (2019). Pengaruh Tingkat Kesehatan Bank Berbasis RGEC terhadap Financial Distress (Studi pada Perusahaan perbankan yang terdaftar di BEI tahun 2015- 2017 ). Diponegoro Journal of Accounting, 8(3), 1-12.

Hutasoit, M. R. F., \& Haryanto, M. (2016). Pengaruh LDR, NPL, BOPO, Ukuran Perusahaan, dan CAR Terhadap Risiko Kebangkrutan Bank (Studi pada Bank Umum Konvensional Periode 2012-2014). Diponegoro Journal of Management, 5(3), 1-13.

Kasmir. (2014). Manajemen Perbankan. Jakarta: PT Raja Grafindo Persada.

Kristanti, F. T. (2014). Prediksi Kebangkrutan Bank-Bank yang Terdaftar di Bursa Efek Indonesia. Jurnal Keuangan dan Perbankan, 18(1), 130-138.

Krugman, P. (1979). A Model of Balance-of-Payments Crises. Journal of Money, Credit and Banking, $11(3), 311-325$.

Kuncoro, S., \& Agustina, L. (2017). Factors to Predict The Financial Distress Condition of the Banking Listed in The Indonesia Stock Exchange. Accounting Analysis Journal, 6(1), 39-47.

Kurniasari, C., \& Ghozali, I. (2013). Analisis Pengaruh Rasio CAMEL dalam Memprediksi Financial Distress Perbankan Indonesia. Diponegoro Journal of Accounting, 2(4), 1-10. 
Lawi, G. F. K. (2019, October 29). BI: Likuiditas Perbankan Masih Terjaga. Financial.Bisnis.Com. https://finansial.bisnis.com/read/20191029/90/1164317/bi-likuiditas-perbankan-masih-terjaga (diakses pada tanggal 16 Desember 2020).

Mahmood, H., Waheed, A., \& Khalid, S. (2014). Role of Macroeconomic Indicators in Banking Crisis. Academic Research International, 5(2), 205-213.

Mayes, D. G., \& Stremmel, H. (2014). The Effectiveness of Capital Adequacy Measures in Predicting Bank Distress. SUERF - The European Money and Finance Forum Study 2014/1, ISBN: 978-3902109-72-9., 3-54.

Messai, A. S., \& Gallali, M. I. (2015). Financial Leading Indicators of Banking Distress : A Micro Prudential Approach Evidence from Europe. Asian Social Science, 11(21), 1-13.

Musdholifah. (2015). Using Index for Predicting Banking Crisis in Asian Countries. International Journal of Empirical Finance, 4(3), 170-183.

Musdholifah, Ismail, M., Kaluge, D., \& Maskie, G. (2013). Predicting Banking Crisis in Six Asian Countries. European Journal of Business and Management, 5 (28), 176-185.

Musdholifah, M., Hartono, U., \& Wulandari, Y. (2020). Banking Crisis Prediction : Emerging Crisis Determinants in Indonesian Banks. International Journal of Economics and Financial Issues, 10(2), 124-131.

Nisaputra, R. (2018, October 24). LPS : LDR Perbankan Masih Cenderung Tinggi Hingga Akhir Tahun. Infobanknews.Com. https://infobanknews.com/topnews/lps-ldr-perbankan-masihcenderung-tinggi-hingga-akhir-tahun/ (diakses pada tanggal 16 Desember 2020).

Nugroho, V. (2012). Pengaruh Camel Dalam Memprediksi Kebangkrutan Bank. Jurnal Akuntansi, $16(1), 145-161$.

Nuranto, A. A., \& Ardiansari, A. (2017). Pengaruh Rasio Keuangan, Firm Size, dan Market Effect Terhadap Tingkat Kebangrutan. Management Analysis Journal, 6(2), 184-194.

Obstfeld, B. M. (1986). Rational and Self-Fulfilling-of-Payment Crises. The Americsn Economic Riview, 76(1), 72-81.

Platt, H. D., \& Platt, M. B. (2002). Predicting Corporate Financial Distress : Reflections on ChoiceBased Sample Bias. 26(2), 184-199.

Prianti, F., \& Musdholifah, M. (2018). Pengaruh RGEC dan variabel makroekonomi terhadap Banking Distress dengan menggunakan CD Indeks di Indonesia. Jurnal Ilmu Manajemen, 6(3), 342-358.

Pristanti, R. N., \& Musdholifah, M. (2020). Pengaruh Risk Based Bank Rating terhadap Financial Distress pada BUSN Non Devisa. Jurnal Ilmu Manajemen, 8(3), 717-733.

Purwohandoko. (2009). Dasar-Dasar Manajemen Keuangan (Teori, Aplikasi dan Kasus). Surabaya: Unesa University Press.

Putri, E. L. (2018). Prediksi Financial Distress dengan Analisis Risk, Good Corporate Governance, Earnings, Capital, dan Size pada Bank Umum Swasta Nasional Devisa. Management and Business Review, 2(2), 93-105.

Rahmaniah, M., \& Wibowo, H. (2015). Analisis Potensi terjadinya Financial Distress Pada Bank 
Wanda Hamidatun Nisak. Pengaruh Rasio RGEC, Bank Size, Market Value, serta Variabel Makro Ekonomi terhadap Prediksi Financial Distress Menggunakan CD-Index

Umum Syariah (BUS) di Indonesia. Jurnal Ekonomi dan Perbankan Syariah, 3(1), 1-20.

Rahmawati, D., \& Khoiruddin, M. (2017). Pengaruh Corporate Governance dan Kinerja Keuangan dalam Memprediksi Kondisi Financial Distress. Management Analysis Journal, 6(1), 1-12.

Rodoni, A., \& Ali, H. (2010). Manajemen Keuangan. Jakarta: Mitra Wacana Media.

Sadida, B. D. (2018). Risk Profile, Good Corporate Governance, Earnings, And Capital ( RGEC ) Sebagai Prediktor Terhadap Kondisi Financial Distress Pada Perusahaan Perbankan. Jurnal Manajemen Bisnis Indonesia, 347-357.

Shidiq, I., \& Wibowo, B. (2017). Prediksi Financial Distress Bank Umum Di Indonesia: Analisis Diskriminan dan Regresi Logistik. Jurnal Bisnis dan Manajemen, 7(1), 27-40. https://doi.org/10.15408/ess.v7i1.4686

Simorangkir, I. (2011). Penyebab Bank Runs Di Indonesia : Bad Luck Atau Fundamental? Buletin Ekonomi Moneter dan Perbankan, 2(3), 51-78.

Siregar, R. I., \& Fauzie, S. (2012). Analisis Manfaat Rasio Keuangan dalam Memprediksi Financial Distress Pada Perbankan (2007-2012). Jurnal Ekonomi dan Keuangan, 2(12), 716-726.

Sofiasani, G., \& Gautama, B. P. (2016). Pengaruh CAMEL Terhadap Financial Distress Pada Sektor Perbankan Indonesia Periode 2009-2013. Journal of Business Management and Enterpreneurship Education, 1(1), 136-146.

Sulastri, E., \& Zannati, R. (2018). Prediksi Financial Distress dalam Mengukur Kinerja Perusahaan Manufaktur. Jurnal Manajemen Strategi dan Aplikasi Bisnis, 1(1), 27-36.

Tandelilin, E. (2010). Portofolio dan Investasi Teori dan Aplikasi (pertama). Yogyakarta: Kanisius.

Theodorus, S., \& Artini, L. G. S. (2018). Studi Financial Distress Pada Perusahaan Perbankan Di Bei. E-Jurnal Manajemen Unud, 7(5), 2710-2732.

Wibowo, B., \& Ham, W. (2016). Dampak Risiko Default Bank terhadap Risiko Sistemik Perbankan dan Risiko Sistematik Bursa Saham di Lima Negara ASEAN. Jurnal Keuangan dan Perbankan, 20 (1), 63-74.

Wulandari, Y., Musdholifah, \& Kusairi, S. (2017). The Impact of Macroeconomic and Internal Factors on Banking Distress. International Journal of Economics and Financial Issues, 7(3), 429-436.

Yacheva, N., Saifi, M., \& Zahroh, Z. A. (2016). Analisis Tingkat Kesehatan Bank Dengan Metode RBBR (Risk-Based Bank Rating) (Studi pada Bank Umum Swasta Nasional Devisa yang Terdaftar di Bursa Efek Indonesia Periode 2012-2014 ). Jurnal Administrasi Bisnis, 37(1), 3745 . 